\title{
Estilos de liderança predominantes em uma indústria madeireira no Meio-Oeste Catarinense: um estudo de caso
}

\author{
Predominant styles of leadership in a wood industry in Santa Catarina: \\ a case study
}

Estilos de liderazgo predominantes en una industria madeira en el Medio-Oeste

Catarinense: un estudio de caso

Recebido em 26/06/2018; revisado e aprovado em 11/10/2018; aceito em 29/10/2018

DOI: http://dx.doi.org/10.20435/inter.v20i3.2062

\author{
Cinara Gambirage ${ }^{1}$ \\ Fellipe Jacomossi ${ }^{1}$ \\ Jaison Caetano da Silva ${ }^{2}$ \\ Nelson Hein ${ }^{1}$
}

\begin{abstract}
Resumo: Este artigo objetiva identificar e discutir os estilos de lideranças predominantes em uma indústria madeireira no Meio-Oeste Catarinense, usando dados primários (questionários aplicados com os gestores) e secundários (balanços patrimoniais da empresa). Para análise dos dados primários, aplicou-se a técnica ANACOR, por meio do software LHStat ${ }^{\circledR}$. Os resultados apontaram que o estilo de liderança transformacional predomina nos gestores da empresa em estudo, poucas vezes fazendo-se presente o estilo laissez-faire.
\end{abstract}

Palavras-chave: Capital humano; Estilos de liderança; Indústria madeireira; Meio-Oeste Catarinense.

Abstract: This article aims to identify and discuss the predominant styles of leadership in a wood industry in Santa Catarina, using primary data (survey applied with managers) and secondary (balance sheets of the company). For analysis of the primary data, was used ANACOR technique through the software LHStat ${ }^{\circledR}$. The results of the research indicate that the transformational leadership style predominates in the managers of the company under study, sometimes the style laissez-faire is present.

Keywords: Human capital; Leadership styles; Wood industry; West of Santa Catarina.

Resumen: Este artículo objetiva identificar y discutir los estilos de liderazgos predominantes en una industria maderera en el Medio Oeste de Catarinense, utilizando datos primarios (cuestionarios aplicados con los gestores) y secundarios (balances patrimoniales de la empresa). Para el análisis de los datos primarios, se aplicó la técnica ANACOR, por medio del software LHStat ${ }^{\circledR}$. Los resultados apuntaron que el estilo de liderazgo transformacional predomina en los gestores de la empresa en estudio, pocas veces haciéndose presente el estilo laissez-faire.

Palabras clave: Capital humano; Estilos de liderazgo; Industria maderera; Medio Oeste Catarinense.

\section{INTRODUÇÃO}

A atenção à importância do capital humano dentro das organizações tem ganhado notoriedade nos estudos de gestão empresarial (MACHADO; CARVALHO, 2006; VIEIRA; APPIO; SLONGO, 2007; GUEDES NOGUEIRA; NETTO MACHADO, 2009, NASCIMENTO; TAKEDA, 2017; ANGELIM; ALENCAR, 2018). Tal notoriedade se deve em grande parte pelo fato de o sucesso ou fracasso de uma organização ser fortemente influenciado, além de outros fatores, pela maneira de liderar seu capital humano (FARIAS; FARIAS; PONTE, 2004; YUKL, 2008).

Em específico, no que diz respeito ao conceito de liderança transformacional-transacional, empregado neste estudo, esse conceito tem sido objeto de diversas pesquisas, inclusive, as que

\footnotetext{
${ }^{1}$ Universidade Regional de Blumenau (FURB), Blumenau, Santa Catarina, Brasil.

${ }^{2}$ Universidade do Vale do Itajaí (UNIVALI), Itajaí, Santa Catarina, Brasil.
} 
o relacionam com aspectos voltados à qualidade de produtos e serviços (JABNOUN; RASASI, 2005), desempenho organizacional (GARCÍA-MORALES; MATÍAS-RECHE; HURTADO-TORRES, 2008) e inovação (JUNG; CHOW; WU, 2003; GUMUSLUOGLU; ILSEV, 2009).

Apesar dos avanços das pesquisas na temática de liderança, há diversas lacunas a serem preenchidas, e estudos no mesmo setor tradicional madeireiro apontam necessidades de contribuições com o campo de pesquisa que ainda é incipiente. Nesse sentido, os achados do estudo de Gambirage, Hahn e Da Silva (2018) apontam o recurso humano na indústria madeireira como uma vantagem competitiva, e a avaliação de competência e comportamentos auxiliam na manutenção desse elemento. Neste sentido, a presente pesquisa pretende contribuir expandindo a literatura ao identificar e discutir os estilos de lideranças predominantes em uma indústria madeireira no Meio-Oeste Catarinense.

A região do Meio-Oeste Catarinense apresenta como característica socioeconômica a concentração de empresas pertencentes ao setor madeireiro. Logo, a região contempla um grande número de empresas madeireiras que estão classificadas entre as maiores empresas brasileiras dessa indústria. Essas empresas possuem tradição nesse âmbito industrial, bem como são representativas em termos de movimentação econômica. Só a Adami S.A., por exemplo, faturou 561.056 milhões de reais em 2016, conforme dados das Demonstrações Financeiras de 2016 constantes no site da empresa (ADAMI S/A, 2016). Nesse contexto, o município de Caçador concentra 23,68\% das empresas e 65,6\% dos empregos desse polo (ÁGAPE, 2014).

Outra característica que representa dificuldade para as empresas na região é falta de mão de obra qualificada (ÁGAPE, 2014). Os colaboradores que constituem empresas desse setor, na região em estudo, remetem-se a um público de classe social baixa, com nível de escolaridade inferior à média, mas que representam um grande número nessas indústrias, inclusive, passando a constituir cargos de liderança em alguns casos (MARTINS et al., 2002). Consequentemente, é um outro público-alvo representativo do objeto de estudo dessa pesquisa, o que torna o estudo dos estilos de liderança predominantes na indústria em análise um tema relevante diante de tais características peculiares aos componentes dessa organização.

Assim, surge a questão problema norteadora deste estudo: Quais os estilos de liderança predominantes em uma indústria madeireira no Meio-Oeste Catarinense? Para estudar a problemática em questão, a pesquisa contou com a aplicação de um questionário aos gestores de uma indústria madeireira no Meio-Oeste catarinense. Tal instrumento objetivou avaliar o estilo de liderança (transformacional, transacional e laissez-faire) de um determinado indivíduo.

Justifica-se a realização deste estudo de duas maneiras: a primeira, na perspectiva teórica, tendo em vista a lacuna de pesquisa observada na literatura, observando que a investigação desse fenômeno por meio de estudos qualitativos poderia aprofundar os debates sobre o tema, contribuindo para um maior embasamento e estado da arte na literatura; e a segunda, na perspectiva gerencial, as evidências desta pesquisa podem ser utilizadas para subsidiar as descrições quanto aos gestores, por exemplo em realocações e capacitações.

Ademais, aponta-se ainda a necessidade de investigar-se a respeito de um tema com pesquisas ainda incipientes. Em termos de contribuição teórica, este estudo fortalece e integra a literatura de capital humano e liderança, estendendo sua aplicação para a indústria madeireira, com foco em empresas de grande porte. O trabalho também contribui para o debate relacionado aos estilos de liderança em organizações no setor madeireiro. Quanto à sua contribuição gerencial, os resultados desta pesquisa também podem ser utilizados no desenvolvimento de 
estratégias corporativas das empresas do setor madeireiro, visto que se valem do estudo de um recurso valioso para as organizações, a liderança. Portanto, tais organizações não devem negligenciar em suas estratégias os estilos de liderança.

\section{REFERENCIAL TEÓRICO}

\subsection{Capital humano}

Os estudos que abordam o capital humano ganharam ênfase na década de 80 com a percepção de gerentes empresariais, acadêmicos e consultores com relação ao papel desenvolvido pelo recurso intangível - capital humano - no desempenho das organizações. Desde então, avançou-se com estudos acerca da relevância do papel do capital humano dentro das empresas (FERRAZ; DERISIO; CRISPIM, 2007).

Uma década após pensar-se sobre a atuação do capital humano e sua relação com o desempenho das organizações, a literatura prospecta com o tema, o que é evidenciado no estudo de Stewart (1998). O capital intelectual resulta da integração do capital humano com o capital estrutural. O primeiro refere-se ao conjunto de conhecimento, habilidades, capacidade de inovação e à capacidade da realização das atividades dos colaboradores, o que ultrapassa a cultura e valores organizacionais, enquanto o segundo corresponde a toda a estrutura organizacional, clientes e relacionamentos marca e tecnologia desenvolvida (LIMA; ZUPPANI; MACLENNAN, 2017).

Stewart (1998), por sua vez, menciona que o capital intelectual, como nova fonte de vantagem competitiva da organização, é dividido em três dimensões denominadas: capital estrutural, capital do cliente e capital humano. Para o autor, o capital estrutural diz respeito à toda estrutura da organização que reproduz/divide tecnologias, invenções, cultura, sistemas, rotinas, dentre outros. O capital do cliente, o mais valioso à organização, refere-se ao fato de a organização conhecer as necessidades de seus clientes de forma a torná-los leais quanto ao produto e/ou serviço consumido. O capital humano, como fonte de inovação, corresponde aos colaboradores da organização que realizam atividades que agregam valor do ponto de vista do cliente.

Em uma perspectiva complementar, Hitt, Ireland e Hoskisson (2002) defendem que o capital humano corresponde ao conjunto de conhecimentos e habilidades dos trabalhadores de uma empresa inteira. Pelo ângulo do capital humano, esses trabalhadores são enxergados como um recurso - capital - em que é preciso investir, valorizar. Ademais, na indústria americana, o capital humano corresponde ao seu desenvolvimento, atribuindo-lhe a eficiência aos resultados.

É perceptível que, até o final da década de 90 , não há consenso na literatura com relação aos elementos que formam o capital intelectual. Entretanto, na Era do Conhecimento, os estudos de Hitt, Ireland e Hoskisson (2002), Tachizawa e Rezende (2002) e Hamel e Prahalad (2005) apontam que o capital humano passa por uma depreciação em virtude do surgimento do novo ambiente competitivo global, pois o capital humano é o responsável pelas transformações que acontecem nos ambientes organizacionais, e isso fez com que as empresas valorassem esse recurso intangível. Logo, essa perspectiva passa a complementar a tradicional avaliação das demonstrações financeiras.

Com a acirrada concorrência, o capital humano pode ser considerado como uma das vantagens competitivas sustentáveis de uma organização. A aprendizagem se relaciona com o desenvolvimento da vantagem competitiva e, por essa razão, cita-se a importância dos programas de desenvolvimento e treinamento, visto que o conhecimento se tornou fator-chave para a 
conquista de vantagem competitiva sustentável. Isto ocorre por meio da construção de conhecimentos e habilidades, à medida que estes oportunizam um conjunto comum de valores centrais e fornecem uma visão sistemática da organização, bem como contribuem para o desenvolvimento de competências essenciais (HITT; IRELAND; HOSKISSON, 2002).

$\mathrm{Na}$ indústria madeireira, destaca-se que, como se trata de um setor em que a matéria-prima é aspecto-chave no dia a dia dessa organização, a indústria passou por várias transformações nas últimas décadas no que diz respeito ao seu maquinário. Isso é reflexo da globalização que permitiu esse avanço tecnológico. Dessa forma, as pessoas nessa organização também começaram a se destacar, contribuindo para com os avanços tecnológicos exigidos desse mercado. Assim, aponta-se a necessidade de observação desse indivíduo, em específico, nesse setor produtivo.

Diante desse novo contexto, as empresas têm buscado formas de continuar sobrevivendo e mantendo-se competitivas no mercado em que atuam. Por consequência, encontram como alternativa para assegurar sucesso e liderança - mesmo que atuem em indústrias tradicionais - a adoção de práticas como o investimento em capital humano, bem como, pesquisa e desenvolvimento (PEREZ; FAMÁ, 2015). Pode-se acrescentar também a importância de conhecer o estilo de liderança que esse capital humano enquadra na organização em que atua, haja vista que está dentro das atividades de pesquisa da organização e contribui para uma melhor gestão da entidade. É sobre esse assunto que se tratará na próxima seção.

\subsection{Liderança}

Os diferentes enfoques que são dados à liderança dificultam o entendimento desse termo de maneira singular, isto é, a elaboração do conceito de liderança é algo complexo de se realizar diante dos diversos significados que a envolvem (BASS, 1990). Logo, a complexidade e a multidimensionalidade são características presentes na liderança quando observada como objeto de estudo. Essa complexidade no processo de liderança pode ser explicada pela abundância e diversidade nas abordagens teóricas apresentadas pelos estudos da área (NORTHOUSE, 2004). Entretanto encontra-se no arcabouço teórico de liderança dos últimos 20 anos uma conceituação desse termo, de modo geral, como um processo facilitador de relações entre as pessoas para que possam efetuar atividades e contribuir para as metas organizacionais (HEIFETZ, 1994; NORTHOUSE, 2004; YUKL, 2008). Assim, nessa mesma linha de pensamento, a liderança é conceituada como ações que permitem influenciar uns aos outros para que se possam atingir os objetivos em comum (NORTHOUSE, 2004).

É importante salientar que, conforme já exposto, na literatura encontram-se várias teorias de abordagem da liderança, dentre elas destacam-se: dos traços, comportamentais, contingenciais, transformacional, autêntica, psicodinâmica, teoria da liderança como trabalho adaptativo, teoria da liderança ética e espiritual. Todavia, neste estudo, será trabalhada apenas a abordagem transformacional, já que é um processo que promulga mudanças e transformações nos indivíduos (NORTHOUSE, 2004).

Primeiramente, a liderança transformacional foi evidenciada no início da década de 70 por Downton, contudo, nos estudos realizados por Burns no final da década de 70, é que a liderança passa a ser considerada como uma abordagem da liderança. Em consequência disso, Burns propõe um modelo (em que distingue líder transacional de transformacional), mas que foi expandido por Bass e colaboradores, os quais classificaram o líder em três estilos: transformacional, transacional e laissez-faire (não liderança) (NORTHOUSE, 2004; YUKL, 2008). 
Cabe aqui expor as características de cada um dos três estilos. O líder transformacional envolve-se com os outros, elevando o nível de motivação no líder e seus seguidores. Em contrapartida, o líder transacional foca suas ações nas técnicas de troca (NORTHOUSE, 2004), assim, cita-se o estabelecimento de uma relação de negócio (BASS, 1997), em que os liderados são motivados pelas promessas, elogios e recompensas do líder (BASS; STEIDLMEIER, 1999). No estilo laissez-faire, não há liderança (BASS, 1990).

Destaca-se, então, que o líder transformacional autêntico atua de forma que instigue seus liderados a realizarem as atividades estabelecidas de forma que ultrapassem o autointeresse. Os seguidores dos líderes transformacionais são incentivados a fazerem além do esperado, assim, podem obter resultados superiores (BASS, 1997).

Bass e Steidlmeier (1999) e Northouse (2004) ainda apontam que cada um dos estilos de líder é caracterizado por um conjunto de comportamentos, são eles: influência idealizada, inspiração motivacional, estimulação intelectual, consideração pelos outros (transformacional), gestão das recompensas, gestão por exceção (transacional) e laissez-faire (não liderança). No Quadro 1, a seguir, constam suas definições e autores representativos.

Quadro 1 - Estilos de Liderança Transformacional (ELT)

\begin{tabular}{|c|c|c|}
\hline ELT & Conceito & Autores \\
\hline $\begin{array}{l}\text { Influência } \\
\text { idealizada }\end{array}$ & $\begin{array}{l}\text { Os líderes demonstram convicção, enfatizam a confiança, tomam } \\
\text { posições sobre questões difíceis, apresentam seus valores mais } \\
\text { importantes e enfatizam a importância do compromisso, propósito } \\
\text { e as consequências éticas das decisões. Esses líderes são admirados } \\
\text { como modelos gerando orgulho, lealdade, confiança e alinhamento } \\
\text { em torno de um propósito comum. }\end{array}$ & Bass (1997) \\
\hline $\begin{array}{l}\text { Inspiração } \\
\text { motivacional }\end{array}$ & $\begin{array}{l}\text { Os líderes articulam uma visão interessante do futuro, desafiam } \\
\text { os seguidores com padrões elevados de desempenho, falam com } \\
\text { otimismo, entusiasmo, incentivam e fornecem sentido ao que } \\
\text { precisa ser feito. }\end{array}$ & Bass (1997) \\
\hline $\begin{array}{l}\text { Estimulação } \\
\text { intelectual }\end{array}$ & $\begin{array}{l}\text { Os líderes questionam velhas hipóteses, tradições e crenças, } \\
\text { estimulam nos outros novas perspectivas e formas de fazer as } \\
\text { coisas e encorajam a expressão de ideias e razões. O líder instiga } \\
\text { os seguidores por meio de questionamentos, criando novas } \\
\text { abordagens para analisar e resolver problemas antigos, estimulando } \\
\text { neles o esforço para a inovação e a criatividade, promovendo uma } \\
\text { mudança na forma de pensar sobre os problemas. }\end{array}$ & $\begin{array}{c}\text { Bass (1997); } \\
\text { Northouse } \\
\text { (2004) }\end{array}$ \\
\hline $\begin{array}{l}\text { Consideração } \\
\text { pelos outros }\end{array}$ & $\begin{array}{l}\text { Os líderes trabalham com outros indivíduos. Eles devem considerar } \\
\text { as necessidades individuais destes, suas capacidades e aspirações } \\
\text { ouvir atentamente, proporcionar o desenvolvimento dos seguidores } \\
\text { e aconselhar. Ensinar e treinar líderes que apresentam esse tipo de } \\
\text { comportamento e podem delegar trabalho aos liderados como uma } \\
\text { forma de ajudá-los a crescer por meio de desafios pessoais. }\end{array}$ & $\begin{array}{c}\text { Bass (1997); } \\
\text { Northouse } \\
(2004)\end{array}$ \\
\hline $\begin{array}{l}\text { Gestão das } \\
\text { recompensas }\end{array}$ & $\begin{array}{l}\text { Os líderes se envolvem em uma transação construtiva de recompensa } \\
\text { por desempenho. Eles esclarecem expectativas, fazem promessas e } \\
\text { oferecem recursos para obter o apoio dos seguidores. Os líderes } \\
\text { transacionais organizam acordos mutuamente satisfatórios. Em si, } \\
\text { a recompensa contingente consiste em um processo de permuta } \\
\text { entre líder e liderados, no qual o esforço dos liderados é trocado } \\
\text { por recompensas específicas. }\end{array}$ & $\begin{array}{c}\text { Bass (1997); } \\
\text { Northouse } \\
(2004)\end{array}$ \\
\hline
\end{tabular}




\begin{tabular}{|c|c|c|}
\hline ELT & Conceito & Autores \\
\hline $\begin{array}{l}\text { Gestão por } \\
\text { exceção }\end{array}$ & $\begin{array}{l}\text { Pode ser ativa ou passiva. Na ativa, os líderes monitoram o } \\
\text { desempenho dos seguidores e tomam ações corretivas quando } \\
\text { ocorrem desvios em relação aos padrões estabelecidos. Eles } \\
\text { impõem regras para evitar erros. Já na passiva, os líderes não } \\
\text { intervêm até que os problemas se tornem graves. Eles esperam que } \\
\text { os problemas sejam levados até eles antes de agir. }\end{array}$ & $\begin{array}{c}\text { Bass (1997); } \\
\text { Bass; } \\
\text { Steidlmeier } \\
\text { (1999) }\end{array}$ \\
\hline Laissez-faire & $\begin{array}{l}\text { O líder procura evitar e não aceitar as suas responsabilidades, ficam } \\
\text { ausentes quando necessário, não dão seguimento a pedidos de } \\
\text { assistência e resistem em expressar as suas opiniões sobre questões } \\
\text { importantes. }\end{array}$ & Bass (1997) \\
\hline
\end{tabular}

Fonte: Adaptado de Tecchio et al. (2010).

Em síntese, a liderança transformacional objetiva promover condições adequadas, calcadas em valores aptos para transformar as organizações e a sociedade, e não somente os indivíduos, de forma a elevar o nível de moralidade individual (TECCHIO et al., 2010).

A liderança é um aspecto que também pode ser observado na indústria madeireira, visto que essa indústria tem sua relevância histórica e econômica nas regiões em que atuam, principalmente na região do Meio-Oeste Catarinense, região em que se encontra a indústria a ser analisada neste estudo. Nesse setor, as lideranças merecem um estudo detalhado em vista das condições em que se formam e características peculiares existentes nas pessoas que constituem essa função.

Diante do exposto, é compreensível a relevância da liderança para essas organizações, especialmente, na indústria madeireira que, devido a sua relevância histórica no processo de desenvolvimento do país, posiciona o Brasil entre os grandes exportadores de madeira do mundo (TEIXEIRA; FIGUEIREDO, 2017).

De modo geral, encontraram-se estudos similares ao tema desta pesquisa, os quais, apesar de estudarem o mesmo mercado, possuem um foco temático parcialmente distinto como é possível observar nos trabalhos de Machado e Carvalho (2006), Vieira, Appio e Slongo (2007), Guedes Nogueira e Netto Machado (2009), Nascimento e Takeda (2017), Angelim e Alencar (2018) e Gambirage, Hahn e Da Silva (2018).

\section{METODOLOGIA DE PESQUISA}

Para identificar os estilos de lideranças predominantes em uma indústria madeireira no Meio-Oeste Catarinense, realizou-se uma pesquisa exploratória e descritiva. Exploratória porque se pesquisou um ambiente organizacional com incipientes atividades acadêmico-científicas no tema proposto. Descritiva, pois identificou, registrou e analisou as variáveis que se relacionaram com o fenômeno em estudo. Quanto ao horizonte de tempo, o estudo é transversal (MARTINS; THEÓPHILO, 2009).

A pesquisa caracteriza-se como um estudo de caso (YIN, 2010), no qual se selecionou a indústria madeireira Sincol S.A., por diversos motivos a saber: a) por sua relevância, haja vista ter se posicionado dentre as 500 maiores empresas da região Sul em uma pesquisa realizada pela Revista Amanhã.com (2015), que avalia vários índices, dentre eles: patrimônio líquido, receita líquida, lucro líquido, receita, patrimônio, capital de giro, liquidez corrente e endividamento sobre o ativo total; b) pela sua longevidade e permanência no mercado, tendo sido fundada a organização no ano de 1943. 
Para consecução deste estudo, foram utilizados dados primários e secundários. Os dados primários referem-se à aplicação de um Questionário de Liderança Multifactor (MLQ-6S), modelo adaptado de Northouse (2004), com perguntas fechadas. As perguntas estavam voltadas a características de líderes que no final classificavam o respondente com seu tipo de liderança predominante dentro do transformacional.

Primeiramente, validou-se o instrumento de coleta dos dados primários com professores especialistas/pesquisadores na área da gestão de recursos humanos. Após isso, aplicou-se o pré-teste do questionário, em três colaboradores da empresa em estudo, com o intuito de identificar possíveis vulnerabilidades no instrumento. O questionário também continha informações relacionadas aos objetivos da pesquisa, quanto ao seu sigilo e uso das informações de modo agregado. Por fim, detectou-se que o instrumento atendia aos objetivos da pesquisa sem necessidade de ajustes.

Após o pré-teste, o questionário foi aplicado, em dezembro de 2016, a todos os gestores de área da empresa Sincol S.A., totalizando 30 respondentes. Os dados secundários da pesquisa contemplam as informações adicionais observadas em documentos oficiais fornecidos pela empresa, como balanços patrimoniais e demonstrações de resultado (dos quais foram retiradas informações de faturamento), bem como informações institucionais constantes do website da organização (que serviu de base para construção da caracterização da empresa em estudo).

Para a análise dos dados primários do estudo, utilizou-se um modelo adaptado de Northouse (2004), que foi aplicado na análise dos questionários. Esse modelo realiza uma avaliação dos estilos de liderança em sete fatores que estão correlacionados com a liderança transformacional. Na Tabela 1, consta o quadro utilizado na análise das informações obtidas nos questionários.

Tabela 1 - Análise do MLQ-6S por fator

\begin{tabular}{|c|c|c|}
\hline & TOTAL* & \\
\hline Influência idealizada (itens 1, 8 \& 15) & & Fator 1 \\
\hline Inspiração motivacional (itens 2, 9 \& 16) & & Fator 2 \\
\hline Estimulação intelectual (itens 3, 10 \& 17) & & Fator 3 \\
\hline Consideração pelos outros (itens 4, 11 \& 18) & & Fator 4 \\
\hline Gestão das recompensas (itens 5, 12 \& 19) & & Fator 5 \\
\hline Gestão pela exceção (itens 6, 13 \& 20) & & Fator 6 \\
\hline Liderança laissez-faire (itens 7, 14 \& 21) & & Fator 7 \\
\hline
\end{tabular}

Nota: Esse campo se refere à tabulação dos resultados das questões agregadas de cada respondente do questionário. Fonte: Adaptado de Northouse (2004).

O Questionário de Liderança Multifatorial (MLQ-6S) avalia a sua liderança em sete fatores relacionados com a liderança transformacional. A sua pontuação em cada fator é determinada somando os três itens especificados no questionário. Por exemplo, para determinar a sua pontuação para o fator 1 , Influência Idealizada, somam-se as pontuações das respostas dos itens 1 , 8 e 15. Esse procedimento é utilizado para os sete fatores. As informações obtidas nessa tabulação foram lançadas em uma planilha de Microsoft Excel ${ }^{\circledR}$ para construção das representações gráficas dos dados.

Na sequência, aplicou-se a técnica de Análise de Correspondências (ANACOR) por meio do software LHStat $^{\circledR}$, no intuito de relacionar os estilos de liderança com o capital humano da 
organização. Segundo Fávero et al. (2009), a técnica ANACOR exibe as associações entre um conjunto de variáveis categóricas não métricas em um mapa perceptual, permitindo, dessa maneira, um exame visual de qualquer padrão ou estrutura de dados. A utilização dessa técnica multivariada justifica-se para facilitar a construção de uma tipologia de indivíduos por meio de variáveis categóricas em análise; observar e resumir a relação entre as variáveis; e ainda, possibilitar a comparação de modalidades das variáveis em análise. Desse modo, a variável de liderança, composta por sete fatores, foi associada à variável capital humano.

A técnica ANACOR se concentra na verificação da associação entre variáveis que são categóricas e que geram tabelas de contingência (MINGOTI, 2005). Quando o número de variáveis e categorias não é grande, usa-se o teste Qui-quadrado para avaliar se a informação contida nas linhas das tabelas é independente ou não das informações contidas nas colunas. Quando o conjunto de dados é maior, como é o caso deste trabalho, o uso da técnica Qui-quadrado fica limitado, pois existe a necessidade de relacionar um grande número de variáveis e categorias. Nesses casos, uma opção é a análise de correspondências (ANACOR).

Fávero et al. (2009) contribuem afirmando "A análise de correspondência (ANACOR) e a análise de homogeneidade (HOMALS) são técnicas de interdependência que buscam estudar a relação entre variáveis qualitativas, permitindo ao pesquisador a visualização de associações, por meio de mapas perceptuais que oferecem a noção de proximidade" (FÁVERO et al., 2009, p. 271). Mais adiante agregam: "a ANACOR é uma técnica que exibe as associações entre um conjunto de variáveis categóricas não métricas em um mapa perceptual, permitindo, dessa maneira, um exame visual de qualquer padrão ou estrutura de dados" (FÁVERO et al, 2009, p. 272).

Matematicamente, parte-se de uma tabela de contingência do tipo:

Tabela 2 - Tabela de Contingência

\begin{tabular}{|c|c|c|c|c|c|c|c|}
\hline & \multicolumn{5}{|c|}{ Variável Y } & \multirow[b]{2}{*}{$q$} & \multirow[b]{2}{*}{ Total } \\
\hline \multirow{6}{*}{ Variável X } & & 1 & 2 & 3 & $\cdots$ & & \\
\hline & 1 & $n_{11}$ & $n_{12}$ & $n_{13}$ & $\ldots$ & $n_{1 q}$ & $\mathrm{n}_{1}$ \\
\hline & 2 & $n_{21}$ & $n_{22}$ & $n_{23}$ & $\ldots$ & $n_{2 q}$ & $\mathrm{n}_{2}$ \\
\hline & 3 & $n_{31}$ & $n_{32}$ & $n_{33}$ & $\ldots$ & $n_{3 q}$ & $n_{3}$ \\
\hline & $\ldots$ & $\ldots$ & $\ldots$ & $\ldots$ & $\ldots$ & $\ldots$ & $\ldots$ \\
\hline & $p$ & $n_{p 1}$ & $n_{p 2}$ & $n_{p 3}$ & & $n_{p q}$ & $\mathrm{n}_{\mathrm{p}}$ \\
\hline Total & & $\mathrm{n}_{.1}$ & $\mathrm{n}_{.2}$ & $\mathrm{n}_{3}$ & $\ldots$ & $n_{. q}$ & $\mathrm{n}=\mathrm{n}$ \\
\hline
\end{tabular}

Fonte: Mingoti (2005).

A matriz de correspondência é uma matriz $P$ de dimensões $p \times q$ construída das proporções $p_{i j}=\frac{n_{i j}}{n}$. A atriz de perfil das linhas é uma matriz diagonal denotada por $\mathrm{D}_{\mathrm{r}^{\prime}}$, cujos elementos diagonais são $r^{\prime}=\frac{n_{1}}{n} \frac{\mathrm{n}_{2}}{\mathrm{n}} \ldots \frac{n_{p}}{n}$. A matriz de perfil das colunas também é diagonal, denotada por $\mathrm{D}_{c^{\prime \prime}}$ cujos elementos diagonais são iguais a $c^{\prime}=\frac{n_{.1}}{n} \frac{n_{.2}}{n} \ldots \frac{n_{q}}{n}$. Considerando a matriz $\tilde{P}=p-r c^{\prime}$ esta matriz tem entradas do tipo $\left(p_{i j}-\frac{n_{. i}}{n} \frac{n_{. j}}{n}\right)$, ou seja, como afirma Mingoti (2005, p. 259), "representam uma comparação da proporção observada no interior de cada cela da tabela, com aquela esperada sob um modelo no qual as variáveis X e Y são independentes". Com efeito, a análise de correspondências múltiplas pode ser tratada pela análise das componentes principais, decompondo-a matriz em seus autovalores e autovetores. 
As coordenadas principais das linhas da matriz $\mathrm{P}$ são dadas por $\mathrm{Y}_{\mathrm{pxq}}=\mathrm{D}_{r}^{-1} \mathrm{~A}_{\mathrm{pxq}} \Lambda_{\mathrm{kxk}}$, e as coordenadas principais das colunas são dadas por $\mathrm{Z}_{\mathrm{pxq}}=\mathrm{D}_{r}^{-1} \mathrm{~B}_{\mathrm{pxq}} \Lambda_{\mathrm{kxk}}$. Mingoti $(2005, \mathrm{p}$. 260) afirma que "as duas primeiras coordenadas principais das linhas e das colunas são as mais representativas em termos de associação" que existe entre as variáveis $\mathrm{X}$ e $\mathrm{Y}$.

\section{RESULTADOS E DISCUSSÃO DO ESTUDO DE CASO}

A organização em estudo denomina-se Sincol Indústria e Comércio S.A., sendo o marco inicial da empresa em 14 de setembro de 1943. Nos primeiros anos de atuação, caracterizava-se por uma pequena fábrica, em Caçador, SC, com apenas 12 colaboradores. É importante destacar que, na década de 50, a madeira era abundante, e o controle ambiental era incipiente. Todavia esse fato não motivou a entidade a deixar de ser uma das pioneiras no manejo florestal e do reflorestamento, por conseguinte a indústria está lastreada em uma reserva própria, conduzida ao longo de sua existência.

Atualmente, a empresa é dirigida por seu diretor, Sr. Carlos Alberto Balvedi, sendo constituída por sua matriz e uma empresa reflorestadora, ambas localizadas em Caçador, SC, uma filial em Jacarezinho, PR, e ainda, uma central de negócios em São Paulo, SP.

No que diz respeito à infraestrutura física, a empresa possui um parque industrial, com cerca de $55.000 \mathrm{~m}^{2}$ de área construída, e dispõe de tecnologia no setor madeireiro. São mais de 1.300 colaboradores que se dedicam a processos tecnológicos e práticas artesanais. A plantação dessa indústria atinge mais de 10.000 hectares de efetivo plantio, tendo seu faturamento no ano de 2016 representado cerca de $\mathrm{R} \$ 105$ milhões.

A empresa atua com vendas em 22 estados brasileiros, sendo a pioneira no Brasil em desenvolver conjuntos de porta pré-montados. Além disso, a empresa de capital nacional, atua com representantes no comércio exterior, possuindo clientes na América do Sul, América Central, América do Norte, Europa e África.

Para analisar a relação das variáveis categóricas estilos de liderança com o capital humano (gestores da organização em estudo), utilizou-se a técnica de Análise de Correspondências Múltiplas (ANACOR) por meio do software LHStat $^{\circledR}$, versão 4.5, conforme mapa perceptual a seguir, após a identificação dos fatores para análise.

A disposição dos pontos oportuniza, graficamente, a análise da associação dos estilos de liderança com o capital humano. Os 30 respondentes estão representados no mapa perceptual por meio das variáveis. A análise procedeu-se pelos estilos de liderança que mais predominam nos gestores da organização em estudo, isto é, os grupos que se constituíram como mais concentrados e mais distantes do centroide nos quadrantes do mapa perceptual (Figura 1). 
Figura 1 - Mapa Perceptual dos Estilos de Liderança associativos ao Capital Humano

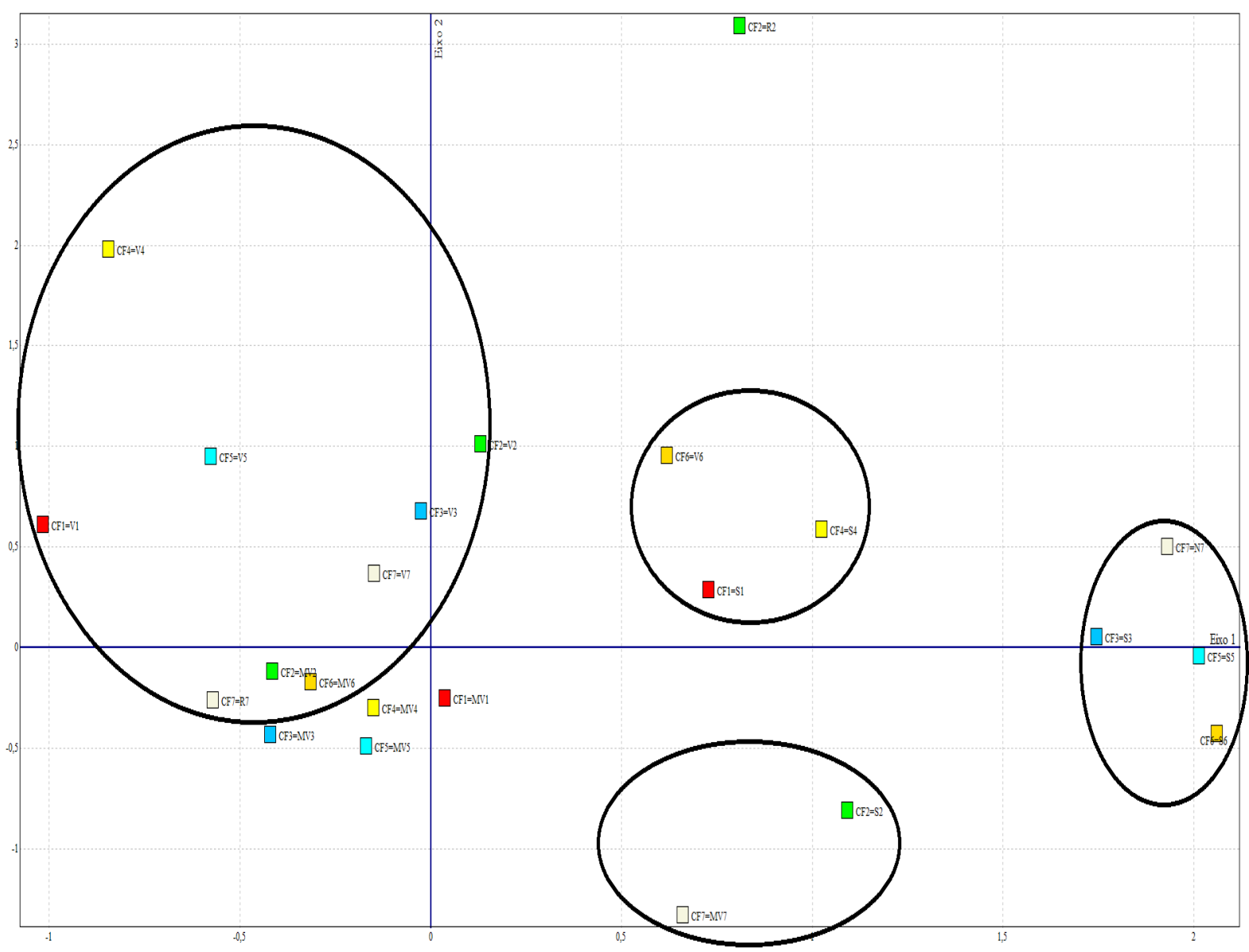

Legenda: CF1_N1= Influência Idealizada nunca; CF1_R1= Influência Idealizada raramente; CF1_V1= Influência Idealizada às vezes; CF1_MV1= Influência Idealizada muitas vezes; CF1_S1=Influência Idealizada sempre; CF2_N2= Inspiração Motivacional nunca; CF2_R2=Inspiração Motivacional raramente; CF2_V2=Inspiração Motivacional às vezes; CF2_MV2=Inspiração Motivacional muitas vezes; CF2_S2= Inspiração Motivacional sempre; CF3_N3= Estimulação Intelectual nunca; CF3_R3= Estimulação Intelectual raramente; CF3_V3= Estimulação Intelectual às vezes; CF3_MV3= Estimulação Intelectual muitas vezes; CF3_S3= Estimulação Intelectual sempre; CF4_N4= Consideração pelos outros nunca; CF4_R4= Consideração pelos outros raramente; CF4_V4=Consideração pelos outros às vezes; CF4_MV4=Consideração pelos outros muitas vezes; CF4_S4= Consideração pelos outros sempre; CF5_N5= Gestão das Recompensas nunca; CF5_R5=Gestão das Recompensas raramente; CF5_V5= Gestão das Recompensas às vezes; CF5_MV5=Gestão das Recompensas muitas vezes; CF5_S5= Gestão das Recompensas sempre; CF6_N6= Gestão por Exceção nunca; CF6_R6= Gestão por Exceção raramente; CF6_V6= Gestão por Exceção às vezes; CF6_MV6= Gestão por Exceção muitas vezes; CF6_S6= Gestão por Exceção sempre; CF7_N7= Laissez-faire nunca; CF7_R7=Laissez-faire raramente; CF7_V7=Laissez-faire às vezes; CF7_MV7=Laissez-faire muitas vezes; CF7_S7=Laissez-faire sempre.

Fonte: Dados da pesquisa (2016).

Portanto o poder associativo entre as variáveis é maior quando tais variáveis estiverem mais afastadas do centroide e mais próximas entre si. Na Figura 1, o mapa perceptual que está dividido em quatro quadrantes. No primeiro, parte superior do lado direito, algumas variáveis estão bem dispersas, as quais apresentam dissimilaridades entre os grupos, em especial, o caso do estilo de liderança laissez-faire, que raramente é presente quando predominam outros estilos em que há controle na gestão (transformacional). Tal resultado vai ao encontro da constatação de Bass (1990), Bass (1997), Northouse (2004) e Yukl (2008), uma vez que, na gestão transformacional, os colaboradores são envolvidos uns com os outros de forma a serem motivados pelo seu líder com atividades que ultrapassam o autointeresse; logo, o resultado é a realização do além 
do esperado. Assim, onde há gestão transformacional, não existe força do estilo laissez-faire, conforme resultado da análise desse primeiro quadrante.

Ainda no primeiro quadrante, nota-se a formação do grupo de estilos de liderança transformacional influência idealizada, consideração pelos outros e gestão por exceção. Esses dois primeiros estilos estão presentes com frequência nos gestores da empresa em estudo e sua relação permite constatar que líderes que geram confiança aos seus liderados, consequentemente, acreditam na capacidade de sua equipe. Ademais, passam a entender suas necessidades individuais o que resulta ainda, mas com menos frequência, em uma gestão por exceção, isto é, a existência de elevado controle na realização de desempenho das atividades de seus liderados. É importante destacar que tal resultado, corroborado com os apontamentos de Bass (1997), Bass e Steidlmeier (1999) e Northouse (2004), agrega estilos de comportamentos diferentes, o que mostra a presença de uma liderança combinada nos gestores da empresa em estudo.

Os achados do segundo quadrante, parte superior ao lado esquerdo, revelam o não agrupamento entre os estilos de liderança predominantes num certo grupo de gestores pesquisados, bem como nota-se uma fraca existência da liderança transformacional nesses respondentes. Entretanto, ainda que fraca a presença de todas as lideranças transformacionais (exceto a gestão das recompensas), o estilo laissez-faire também às vezes acontece nesse grupo. Sinteticamente, não há um estilo de liderança predominante nesse grupo de respondentes. A literatura não suporta tal resultado, mas, ainda assim, o achado merece análises em aprofundamento para melhor compreensão desse fenômeno. Revela-se aqui uma limitação do estudo, na medida em que os recursos metodológicos utilizados nesta pesquisa não fornecem um embasamento para tentar explicar tal ocorrência.

No terceiro quadrante, parte inferior do lado esquerdo, apesar de as variáveis categóricas estarem muito próximas do centroide, nota-se uma forte associação entre elas. Todos os estilos de liderança transformacional predominam com frequência nesse grupo de respondentes; todavia o estilo sem liderança (laissez-faire) não está presente nesse caso. Esse achado corrobora a afirmação de Northouse (2004) e Yukl (2008), inclusive tal inferência já foi explicitada nos resultados do primeiro quadrante.

O quarto quadrante, parte inferior do lado direito, também mostra dispersão das variáveis. Mas, ainda assim, revela um resultado interessante. Mesmo com a forte existência da gestão por inspiração motivacional, o estilo laissez-faire acontece muitas vezes nesse grupo de liderados. Para melhor compreender esse fenômeno, tenta-se justificar pelo fato de que, quando os líderes que motivam fortemente seu grupo propõem desafios audaciosos, também apresentam características de liderança ausente, quando necessárias, justamente por revelar uma visão interessante do futuro. Entende-se que, nesse caso, os liderados precisam de um "respiro" para colocarem em prática os desafios que lhes são propostos, afinal, nem todos os colaboradores agem com bom desempenho em lideranças apenas controladoras. Esse resultado vai de encontro à literatura de Northouse (2004) e Yukl (2008) em que expõem acerca das diferenças existentes entre esses estilos. Esse resultado permite salientar que, mesmo não sendo apontada sua relação pela literatura, na prática empresarial tal fenômeno acontece e pode ser um dos motivos dos resultados satisfatórios que a empresa do setor obtém, mas, para uma confirmação dessa constatação, seria necessário um estudo focado nesse aspecto para melhor explorar tal fenômeno.

Uma última análise realiza-se acerca de um novo grupo que se forma, unindo dois quadrantes: o primeiro e o quarto. Três estilos de liderança - estimulação intelectual, gestão das 
recompensas e gestão por exceção - ocorrem com alta frequência, enquanto o laissez-faire deixa de acontecer nesse caso. Os três estilos não possuem relação alguma com a àusência de liderança; por isso, o referido resultado. Um líder ausente, raras vezes, interferirá com questionamentos e hipóteses os seus liderados, também dificilmente fornecerá estímulos e recompensas aos seus liderados (já que nunca está presente), assim como não procurará entender as necessidades individuais de sua equipe em virtude de sua ausência; o que realmente importa, para esse líder é o desempenho de sua equipe. Esses resultados confirmam as abordagens de Bass (1997), Bass e Steidlmeier (1999), Northouse (2004) e Yukl (2008).

Diante de tal análise, é possível perceber que os estilos de liderança transformacionais são os que predominam nos gestores da organização em estudo. Poucas vezes, fazendo-se presente o estilo laissez-faire. Tendo em visa que os colaboradores da empresa indústria madeireira trabalham, diariamente, por produção, torna-se compreensível o motivo de tal resultado, pois necessita-se de uma gestão ativa, presente e, por vezes, controladora de forma que as atividades sejam cumpridas em escala, já que se trata de uma indústria de grande porte com abertura para o mercado internacional.

Portanto os resultados dessa pesquisa permitem coadunar com os apontamentos de Hitt, Ireland e Hoskisson (2002) em que expõem acerca da valoração do capital humano, torna-se essencial para que o fluxo permaneça contínuo, principalmente nesse tipo de organização em que o trabalho manual ainda se faz presente, exigindo confiança e inspiração dos trabalhadores para permanecerem em suas atividades.

\section{CONSIDERAÇÕES FINAIS}

O estudo consistiu em identificar e discutir os estilos de lideranças predominantes em uma indústria madeireira no Meio-Oeste Catarinense. A análise da evidência desse fenômeno apontou que os estilos de liderança mais presentes nos gestores da indústria madeireira em estudo são os transformacionais. Apenas em alguns casos, ocorre a presença do estilo laissez-faire.

Esse resultado leva à conclusão de que, por se tratar de uma empresa do setor madeireiro em que as atividades dos colaboradores precisam ser gerenciadas continuamente de forma que se cumpra com a produtividade organizacional, o estilo de liderança transformacional, desde a Influência Idealizada até a Gestão por Exceção, apresenta características que se enquadram para tal contexto em estudo. Apesar da presença de laissez-faire, ainda assim há gestores transformacionais que procuram manter-se atuantes na gestão.

Os achados desta pesquisa revelaram uma contribuição teórica e prática para o tema analisado. Na perspectiva teórica, o estudo contribui para a literatura uma vez que se observou a necessidade de realização de estudos que tratassem desse tema, tendo como unidade de análise o setor madeireiro. $O$ acontecimento da presença de dois estilos de liderança distintos em um mesmo ambiente revelou contrastes com o arcabouço teórico exposto, o que representa interessantes achados que podem gerar debates significativos na literatura de capital humano e liderança no setor madeireiro. Portanto o trabalho fortalece e integra a literatura de capital humano e liderança, estendendo sua aplicação para a indústria madeireira, com foco em empresas de grande porte. Na perspectiva empírica, o estudo contribui ao revelar resultados que podem ser utilizados gerencialmente, inclusive como tentativa de entender profundamente, a 
ocorrência de alguns fenômenos em especial, encontrados nos resultados da pesquisa. Os achados desta pesquisa também podem ser utilizados no desenvolvimento de estratégias corporativas das empresas do setor madeireiro, visto que se valem do estudo de um recurso valioso para as organizações, o recurso humano. Portanto tais organizações não devem negligenciar em suas estratégias os estilos de liderança presentes em seu ambiente.

É salutar mencionar que este trabalho apresenta limitações que não permitiram confirmar alguns resultados, bem como explicar, em profundidade, alguns achados. Um exemplo seria o resultado encontrado no segundo quadrante, em que se nota uma fraca existência da liderança transformacional (exceto a gestão das recompensas), além de o estilo laissez-faire também às vezes aparecer nesse grupo. Tal acontecimento pode ser decorrente de vários fatores, inclusive por alguma fragilidade no instrumento de coleta de dados, não permitindo suportar algumas inferências. O fato de se pesquisar apenas a visão da gestão sem considerar o posicionamento dos liderados também é uma limitação desta pesquisa, o que não permitiu análises mais específicas nos resultados obtidos.

Sugere-se, então, que, em estudos futuros, seja considerada a percepção dos liderados que constituem a equipe dos gestores de forma a melhorar a análise; incluam-se outras empresas do mesmo setor; opte-se também por outros instrumentos de coletas de dados como a entrevista - por exemplo, e outras técnicas estatísticas que possam complementar as análises.

\section{AGRADECIMENTOS}

Os autores agradecem ao Programa UNIEDU Pós-Graduação e à Coordenação de Aperfeiçoamento de Pessoal de Nível Superior (CAPES).

\section{REFERÊNCIAS}

ADAMI S/A. Demonstração financeira. 2016. Disponível em: https://www.adami.com.br/investidores/ demonstracao-financeira/. Acesso em: 18 ago. 2017.

SANTA CATARINA (estado). Secretaria de Desenvolvimento Econômico Sustentável de Santa Catarina; Serviço de Apoio às Micro e Pequenas Empresas de Santa Catarina (Sebrae/SC). Estudo Setorial da Indústria Catarinense. Florianópolis: SDS; SEBRAE-SC, 2014. Disponível em: http://www.bibliotecas.sebrae.com. br/chronus/ARQUIVOS_CHRONUS/bds/bds.nsf/3269f3d0a2acc0ba4fe866fd35a93344/\$File/5750.pdf. Acesso em: 10 set. 2016.

GRUPO AMANHA. 500 maiores do Sul. 2015. Disponível em: http://www.amanha.com.br/500maiores/. Acesso em: 19 dez. 2016.

ANGELIM, E. G. D.; ALENCAR, O. L. G. Satisfação no ambiente de trabalho dos funcionários da Madeireira Três Irmãos. Revista de Administração da UNI7, Fortaleza, v. 2, n. 1, p. 13-49, 2018.

BASS, B. Bass e Stogdill's Handbook of Leadership: theory, research, and managerial applications. 3. ed. New York: The Free Press, 1990.

BASS, B. Does the Transactional-Transformational Leadership Paradigm Transcend Organizational and National Boundaries? American Psychologist, v. 52, n. 2, p. 130-9, fev. 1997.

BASS, B.; STEIDLMEIER, P. Ethics, character, and authentic transformational leadership behavior. The leadership quarterly, v. 10, n. 2, p. 181-217, 1999. 
FARIAS, F. S. O.; FARIAS, I. Q.; PONTE, V. M. R. Gerenciamento do capital intelectual: um estudo em empresas do setor têxtil Cearense. In: ENCONTRO NACIONAL DOS PROGRAMAS DE PÓS-GRADUAÇÃO EM ADMINISTRAÇÃO - EnANPAD, 28., Curitiba, PR, 2004. Anais [...] Curitiba: EnANPAD, 2004.

FÁVERO, L. P.; BELFIORE, P.; SILVA, F. L.; CHAN, B. L. Análise de dados: modelagem multivariada para tomada de decisões. Rio de Janeiro: Elsevier, 2009.

FERRAZ, S.; DERISIO, D. P. L.; CRISPIM, S. F. Capital humano: fonte de vantagem competitiva? A visão de duas organizações do setor farmacêutico. In: ENCONTRO DE GESTÃO DE PESSOAS E RELAÇÕES DE TRABALHO - ENGPR, 1., Natal, RN, 2007. Anais [...]. Natal: EnGPR, 2007.

GAMBIRAGE, C.; HAHN, I. S.; DA SILVA, J. C. Recursos estratégicos e vantagem competitiva na indústria madeireira catarinense. Revista Inteligência Competitiva, São Paulo, v. 8, n. 2, p. 56-84, 2018.

GARCÍA-MORALES, V.; MATÍAS-RECHE, F.; HURTADO-TORRES, N. Influence of transformational leadership on organizational innovation and performance depending on the level of organizational learning in the pharmaceutical sector. Journal of Organizational Change Management, v. 21, n. 2, p. 188-212, 2008.

GUEDES NOGUEIRA, C. E.; NETTO MACHADO, D. D. P. Traços culturais de pequenas empresas do setor madeireiro. Gestão \& Regionalidade, São Caetano do Sul, v. 22, n. 65, 2009.

GUMUSLUOGLU, L.; ILSEV, A. Transformational leadership, creativity, and organizational innovation. Journal of Business Research, v. 62, n. 4, p. 461-73, 2009.

HAMEL, G.; PRAHALAD, C. K. Competindo pelo futuro: estratégias inovadoras para obter o controle do seu setor e criar os mercados de amanhã. Tradução de Outras Palavras. 19. ed. Rio de Janeiro: Elsevier, 2005.

HEIFETZ, R. Leadership without easy answers. Cambridge, Massachusetts: The Belknap Press of Harvard University, 1994.

HITT, M. A.; IRELAND, R. D.; HOSKISSON, R. E. Administração Estratégica: competitividade e globalização. Tradução de José Carlos Barbosa dos Santos e Luiz Antônio Pedroso Rafael. São Paulo: Pioneira Thomson Learning, 2002.

JABNOUN, N.; RASASI, A. Transformational leadership and service quality in UAE hospitals. Managing Service Quality, v. 15, n. 1, p. 70-81, 2005.

JUNG, D.; CHOW, C.; WU, A. The role of transformational leadership in enhancing organizational innovation: hypotheses and some preliminary findings. The Leadership Quarterly, v. 14, n. 4-5, p. 525-44, 2003.

LIMA, L. C.; ZUPPANI, T. S.; MACLENNAN, M. L. F. Human Resource Management in the BRICS countries: a comparative study. Interações, Campo Grande, MS, v. 18, n. 3, p. 69-82, 2017.

MACHADO, D. D. P. N.; CARVALHO, C. E. Traços culturais de pequenas empresas do setor madeireiro. Revista Ciências Administrativas, Fortaleza, v. 12, n. 1, 2006.

MARTINS, G. A.; THEÓPHILO, C. R. Metodologia da investigação cientifica para ciências sociais aplicadas. 2. ed, São Paulo: Atlas, 2009.

MARTINS, E. P.; VIEIRA, A. H.; LOCATELLI, M.; OLIVEIRA, V. B. V.; PEQUENO, P. L. L. Perfil dos funcionários e condições de trabalho nas indústrias madeireiras do município de Jaru-RO. Porto Velho: Embrapa-CPAF Rondônia, 2002. 
MINGOTI, S. A. Análise de dados através de métodos de estatística multivariada: uma abordagem aplicada. Belo Horizonte: UFMG, 2005.

NASCIMENTO, E. P.; TAKEDA, W. M. O Setor Florestal e a busca pela sustentabilidade. Somanlu: Revista de Estudos Amazônicos, Manaus, v. 13, n. 2, p. 80-94, dez. 2017.

NORTHOUSE, P. G. Leadership: theory and practice. 3. ed. California: Thousand Oaks, 2004.

PEREZ, M. M.; FAMÁ, R. Características estratégicas dos ativos intangíveis e o desempenho econômico da empresa. Unisanta Law and Social Science, Santos, v. 4, n. 2, p. 107-23, 2015.

STEWART, T. Capital Intelectual: a nova vantagem competitiva das empresas. 6. ed. Rio de Janeiro: Campus, 1998.

TACHIZAWA, T.; REZENDE, W. Estratégia empresarial: tendências e desafios - um enfoque na realidade brasileira. São Paulo: Makron Books, 2002.

TECCHIO, E. L.; NUNES, T. S.; RISSI, M.; NAKAYAMA, M. K. Liderança transformacional em processos de tutoria: a identificação do estilo de liderança de orientadores de tutoria. Renote - Revista Novas Tecnologias na Educação, Porto Alegre, v. 8, n. 3, p. 1-11, 2010.

TEIXEIRA, M. D. J.; FIGUEIREDO, A. M. R. Análise intersetorial e espacial da cadeia produtiva da madeira e móveis na economia de Mato Grosso: uma contribuição para identificação de APLS. Revista Brasileira de Gestão e Desenvolvimento Regional, Taubaté, v. 13, n. 2, p. 103-28, 2017.

VIEIRA, V. A.; APPIO, J.; SLONGO, L. A. Uma análise dos antecedentes da satisfação no trabalho em uma empresa madeireira. REGE Revista de Gestão, São Paulo, v. 14, n. 3, p. 1-18, 2007.

YIN, R. K. Estudo de caso: planejamento e métodos. 4. ed. Porto Alegre: Bookman, 2010.

YUKL, G. Liderazgo en las organizaciones. 6. ed. Madrid: Prentice Hall, 2008.

\section{Sobre os autores:}

Cinara Gambirage - Doutoranda em Ciências Contábeis e Administração pela Universidade Regional de Blumenau (FURB). Mestre em Administração pela Universidade do Sul de Santa Catarina (UNISUL). Especialista em Docência na Educação a Distância pela FAE Centro Universitário. Graduada em Letras trilíngue pela Universidade Alto Vale do Rio do Peixe (UNIARP). Graduanda em Administração pela UNIARP. Docente nos cursos de graduação na UNIARP, de Caçador, SC. E-mail: naraboniii_@hotmail.com, Orcid: http://orcid.org/0000-0002-8166-1171

Fellipe Jacomossi - Doutorando em Ciências Contábeis e Administração, e Mestre em Ciências Contábeis pela Fundação Universidade Regional de Blumenau (FURB). Graduação em Administração, Ciências Contábeis e Direito pelo Centro Universitário de Brusque (UNIFEBE). Técnico em Transações Imobiliárias pelo Instituto Brasileiro de Educação Profissional (IBREP). Proficiência avançada em Inglês pela instituição St. Giles International - Brighton, Inglaterra. E-mail: fellipejacomossi@gmail.com, Orcid: http://orcid.org/0000-0002-8737-152X

Jaison Caetano da Silva - Doutorando em Administração pela Universidade do Vale do Itajaí (UNIVALI). Mestre em Administração pela Universidade do Sul de Santa Catarina (UNISUL). 
Especialização em andamento em Gestão Estratégica de Finanças, Contabilidade e Controladoria pela Universidade Alto Vale do Rio do Peixe (UNIARP). Graduado em Matemática e em Administração pela UNIARP. E-mail: jaisoncsilva@hotmail.com, Orcid: http://orcid.org/0000-0002-8737-152X

Nelson Hein - Pós-Doutorado pelo Associação Instituto Nacional de Matemática Pura e Aplicada (IMPA) e pela Anderson School of Management da Universidade do Novo México (EUA). Doutorado e Mestrado em Engenharia de Produção pela Universidade Federal de Santa Catarina (UFSC). Especialista em Ensino de Ciências / Matemática pela Universidade Regional de Blumenau (FURB). Graduado em Ciências e em Matemática pela FURB. Professor do Departamento de Matemática e professor permanente no Programa de Pós-Graduação em Ciências Contábeis (PPGCC) da FURB. Coordena o grupo de Estudos MULTIVAR. E-mail: hein@furb.br, Orcid: http://orcid.org/0000-0002-8350-9480 